\title{
O feminino pulsante no videoclipe Afeminada de $\mathrm{CTRL}+\mathrm{N}$
}

\author{
Adriana do Carmo Figueiredo ${ }^{\mathrm{i}}$ \\ Fábio Ávila Arcanjo ${ }^{\text {ii }}$
}

\begin{abstract}
RESUMO
Afeminada é uma obra artística focada na resistência. No entanto, resistência contra o quê? A dupla paraense CTRL+N elenca de um lado a heteronormatividade repressora e, de outro lado, o condicionamento comportamental construído no interior da comunidade LGBT+ como adversários a serem enfrentados. Para combater esse estado de coisas, a dupla disponibilizou um videoclipe que lança mão de duas estratégias discursivas: a plasticidade axiológica, fundamentada em Paveau (2015), e a ironia, problematizada em Machado (2014). Importante destacar a noção de imaginários sociodiscursivos, proposta por Charaudeau (2013), que perpassa o acionamento das estratégias mencionadas. Esta é a trajetória teórica e metodológica da nossa pesquisa que abordará ainda algumas discussões sobre Bioética e Direitos Humanos.
\end{abstract}

Palavras-chave: Análise do discurso; Diversidade; Bioética; Direitos humanos.

\begin{abstract}
Afeminada is a masterpiece that focuses on resistance. But resistance to what? A duo from form Pará named CTRL+N lists repressive heteronormativity contrasted with the behavioral pattern built within the LGBT+ community portraying them as opponents. To fight against this situation, the duo recorded a video clip that uses two discursive strategies: axiological plasticity, based on Paveau (2015), and the irony, discussed by Machado (2014). It is important to highlight the concept of the socio-discursive imaginary, proposed by Charaudeau (2013), which permeates the activation of the mentioned strategies. This is the theoretical and methodological trajectory of our research that will also address some discussions on Bioethics and Human Rights.
\end{abstract}

Keywords: Discourse analysis; Diversity; Bioethics; Human rights.

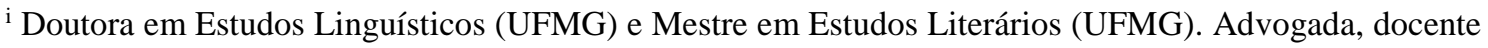
e pesquisadora de Linguagens, Discurso, Teorias da Argumentação, Direitos Humanos, Bioética e Hermenêutica Jurídica. É membro da Sociedade Brasileira de Retórica (SBR) e da Associação Latinoamericana de Estudos do Discurso (ALED).

ORCID: https://orcid.org/0000-0001-5653-5731 | acfigueiredo.prof@gmail.com

ii Doutorando em Linguística do Texto e do Discurso (UFMG), Mestre em Estudos Linguísticos (UFMG) e Bacharel em Comunicação Social. Membro da Sociedade Brasileira de Retórica (SBR) e da Associação Latino-americana de Estudos do Discurso (ALED). Desenvolve pesquisas acadêmicas em Análise do Discurso, Retórica e Teorias da Argumentação. ORCID: https://orcid.org/0000-0002-8525-9737 | fabioarcanjo81@ gmail.com
} 


\section{INTRODUÇÃO}

Este artigo é fruto de uma comunicação que apresentamos no III Congresso de Diversidade Sexual e de Gênero, $2^{\text {a }}$ edição internacional, evento organizado pelos Programas de Pós-Graduação em Direito da UFMG e em Direito e Educação da UFOP. O encontro acadêmico ocorreu entre os dias 31 de outubro e 03 de novembro de 2018 , na cidade de Ouro Preto, Minas Gerais.

A nossa participação no referido evento trouxe como foco de discussão o videoclipe da música Afeminada, disponibilizado nas redes sociais no dia 13 de julho de 2018. Trata-se de uma composição em coautoria dos músicos paraenses Nigel Anderson e Haroldo França, conhecidos como dupla CTRL+N. O videoclipe da música Afeminada foi lançado no canal oficial dos artistas no Youtube e em outros sites da internet, com a descrição: “Sai, macho astral! Que tal abrir janelas de visibilidade?".

Assim, com essa mensagem inaugural de espantar o "macho astral" e de sair da invisibilidade, o objetivo do videoclipe parece sugerir uma tentativa de celebrar o mês da visibilidade LGBT+, em julho de 2018, indicando a urgência de uma reflexão sobre a arte que traz "as dores e os prazeres de fazer música do lugar das bichas", conforme extraímos das informações veiculadas pelo DOL - portal diarioonline - . Vejamos:

De uma tentativa despretensiosa de celebrar [o] mês da visibilidade LGBTQIA+ a um caminho de arte empoderadora. Nigel Anderson e Haroldo França, paraenses radicados em São Paulo há mais de 5 anos, revelam com $\mathrm{CTRL}+\mathrm{N}$ as dores e os prazeres de fazer música do lugar das bichas. Eles lançaram nesta sexta-feira (13) a música "Afeminada" com videoclipe. (DOL, acesso em 13 jul. 2018)

Ainda segundo informações divulgadas no DOL, o videoclipe Afeminada

[...] chama atenção para a exaltação do feminino no corpo masculino. O nome CTRL+N corresponde ao comando de abrir uma nova janela no computador e o intuito da dupla é este, escancarar a visibilidade por respeito e amor das suas diversas formas. (DOL, acesso em 13 jul. 2018)

Com esse propósito, é possível pensar que estamos diante de uma convocação militante, uma vez que os autores colocam em evidência uma causa social, a saber, o direito da minoria LGBT+. Entretanto, a mensagem parece se voltar não apenas para um grupo inserido dentro da supracitada comunidade, grupo esse que, por vezes, é ainda 
mais estigmatizado, mas também para um convite amplamente aberto pela pergunta introdutória "Que tal abrir janelas de visibilidade?".

Ao que parece ser, essas janelas que escancaram a (in)visibilidade, conforme sugerem os músicos paraenses, trazem também a convocatória de mais respeito por essa “ode feminina que há no homem gay". Nesse sentido, afirma Nigel Anderson:

\begin{abstract}
"O feminino é pulsação e identidade, mesmo no corpo masculino. Esse feminino, quando colocado pra fora, precisa ser respeitado - dentro e fora do meio. Quando vemos uma rejeição acontecer entre nossos contemporâneos, e mesmo com a gente, percebemos que não se tratam ( sic) de violências isoladas. É um sistema normativo que violenta muitas e muitos sistemicamente - e é exatamente essa norma que queremos combater, a partir de nosso lugar de fala". ([Fala de Nigel Anderson] DOL, acesso em 13 jul. 2018, aspas do original)
\end{abstract}

É possível sintetizar, portanto, que Afeminada é um trabalho feito por afeminados, sobre afeminados, e direcionado tanto para aqueles que se enquadram na categoria, como para um público alheio a tal "classificação". E, ainda, é possível indagar se o videoclipe apresenta uma resposta à incorporação do totalitarismo heteronormativo pela comunidade LGBT+. Se essa hipótese se confirma, seria possível pensar nas lutas pelo respeito e pela visibilidade como constantes, tendo em vista que as mudanças nos discursos hegemônicos demoram a ocorrer, em razão das penetrações ideológicas dominantes nos discursos dos dominados.

Desse modo, julgamos pertinente apresentar alguns eixos temáticos a serem percorridos em nosso texto, chamando a atenção para o fato de estarmos atrelados à área da Análise do Discurso de linha francesa, um campo do saber de caráter transdisciplinar. Partiremos do conceito de plasticidade axiológica, desenvolvido por Paveau (2015), dos imaginários sociodiscursivos, conforme a teoria semiolinguística de Charaudeau (2013[2009]) e dos elementos que compõem os jogos irônicos na discursivização do corpus examinado, de acordo com Machado (2014). Esse compósito de teorias discursivas servirá de base para explicitarmos alguns preceitos extraídos da Declaração Universal sobre Bioética e Direitos Humanos (2005), o que nos leva a refletir, também, sobre as noções relativas à moral autorreferente e moral intersubjetiva, de acordo com a filosofia do jurista argentino Carlos Santiago Nino (2017, [1984]). 


\section{A DISCURSIVIDADE VIRTUOSA E OS IMAGINÁRIOS SOCIODISCURSIVOS}

Marie-Anne Paveau (2015) observa que os discursos produzidos são submetidos a ajustes, levando em consideração os imaginários sociodiscursivos circulantes em uma determinada época e em uma determinada sociedade. Para Patrick Charaudeau, tais imaginários “[...] dão testemunho das identidades coletivas, da percepção que os indivíduos e os grupos têm dos acontecimentos, dos julgamentos que fazem de suas atividades sociais" (CHARAUDEAU, 2013, p. 207). O que se percebe, com base no excerto anterior, é uma adequação para o que a pesquisadora francesa nomeia de virtude discursiva, que seria "[...] uma disposição do agente em produzir discursos ajustados aos valores vigentes em seu ambiente" (PAVEAU, 2015, p. 275).

Existe um grau de complementaridade entre os dois conceitos apresentados. Os imaginários sociodiscursivos estão inseridos em um espaço de interdiscursividade, funcionando na organização dos saberes a partir de um espaço demarcado, tanto no ponto de vista das ideias, quanto no que tange aos valores. O linguista francês afirma que "[...] à medida que esses saberes, enquanto representações sociais, constroem o real como universo de significação, segundo o princípio de coerência, falaremos de “imaginários"” (CHARAUDEAU, 2013, p. 203). Eles são discursivos, pois são identificados por meio da produção de enunciados linguageiros, e o acréscimo do item lexical "sócio" se dá em função da circulação de tais enunciados em determinados grupos sociais. A interação com o conceito de virtude discursiva se dá nos ajustes a serem realizados para a circulação dos enunciados. De certa forma, um discurso pode ser considerado virtuoso se ele, atuando em uma margem de manobra, tiver respeitado as regras de formulação inscritas no contrato de comunicação, que, para Charaudeau, “[...] pressupõe que os indivíduos pertencentes a um mesmo corpo de práticas sociais estejam suscetíveis de chegar a um acordo sobre as representações linguageiras" (CHARAUDEAU, 2012, p. 56).

O "ajuste" mencionado pela pesquisadora francesa pode ser obtido por meio da ressignificação, ou seja, "desajustando” a carga semântica de determinado item lexical. Esse mecanismo pode ser percebido em manifestações culturais produzidas por 
movimentos compostos por minorias, como a música Afeminada. Os elementos discursivos dessa música, alinhados às imagens do videoclipe, se enquadram na estratégia da plasticidade axiológica, cuja ideia é possibilitar aos agentes “[...] brincar com os valores das palavras, que só são lidas e inscritas nos discursos a partir dos dados do ambiente" (PAVEAU, 2015, p. 326).

Diante do que foi apresentado, podemos pensar que a plasticidade axiológica é uma atividade linguageira que opera a partir de um processo de deslizamento entre os imaginários sociodiscursivos e a virtude discursiva. Ela atuaria nas arestas presentes no contrato de comunicação, permitindo "alargar" os horizontes de possibilidades semânticas. Explicando melhor: ao afirmar que Afeminada seria um contradiscurso, estamos evidenciando a existência de discursos que se colocam em polos antagônicos, isto é, temos a presença de um discurso de resistência lutando contra um discurso hegemônico. O objetivo, portanto, é aumentar o espaço de inscrição que legitimaria a existência de mensagens similares àquelas que se fazem presentes no trabalho da dupla paraense.

Podemos destacar duas relações antagônicas: a primeira opõe o discurso LGBT+ ao discurso hegemônico heteronormativo; a segunda, a nosso ver mais curiosa, contrapõe comportamentos vistos como desejáveis pela comunidade LGBT+ em relação àqueles considerados apelativos por membros da própria comunidade. Há, a partir desse quadro, um duplo papel de resistência: contra o discurso hegemônico heteronormativo e contra um suposto discurso centralizador e direcionador construído no interior de uma formação discursiva situada nos liames da comunidade LGBT+.

Charaudeau (2015) observa que a tomada de consciência identitária está atrelada à percepção de uma diferença, isto é, “[...] somente percebendo o outro como diferente que pode nascer a consciência identitária" (CHARAUDEAU, 2015, p. 18). Diante dos movimentos de atração e rejeição observados pelo autor francês, percebemos a existência de uma espécie de "cabo de força", que visaria construir um "espaço de manobra" para uma possível afirmação identitária. A "rejeição" se dá a partir do momento em que a diferença é interpretada como uma ameaça (CHARAUDEAU, 2015). A consequência seria a construção de julgamentos negativos, que visariam silenciar determinados grupos de resistência. 
Voltando o nosso olhar para a segunda relação antagônica, percebemos na letra da canção e nas imagens, como um todo, que o ponto fulcral exaltado pela música e pelo videoclipe Afeminada é, na maioria das vezes, combatido por membros da própria comunidade LGBT+. O pesquisador brasileiro Venan Alencar assevera que há uma proeminente valorização de um comportamento, por parte de membros da comunidade gay masculina, que emularia a virilidade e a hipermasculinidade. Para o autor, a construção dessa imagem "masculina" é proveniente do discurso hegemônico que traça “[...] padrões de masculinidades e, na subcultura gay, isso se tem mostrado também constante, [...] como formas de (re)afirmação de uma virilidade que estaria constantemente posta à prova" (ALENCAR, 2017, p. 67).

Destaquemos o fato de que no interior daquilo que é nomeado de "subcultura gay" parece adentrar uma espécie de contrato limitador "não escrito". É justamente esse o combate travado pelos autores da música Afeminada, pois os homossexuais, quando trazem como característica um afloramento pulsante do comportamento feminino, acabam sendo, muitas vezes, relegados e discriminados não apenas pelas malhas heteronormativas, mas também pelos seus próprios pares nas lutas LGBT+. Alencar (2017) percebe tal comportamento no perfil de usuários de aplicativos de relacionamento entre homossexuais. Em sua dissertação de mestrado, ele observa que, em grande parte dos perfis analisados em sua pesquisa, há uma busca por homossexuais com traços viris e que, como consequência, não sejam "afeminados". Retomando o nosso material de análise, percebemos que a contraposição construída pela dupla paraense se dá por meio da utilização de duas estratégias: a plasticidade axiológica e a ironia.

\section{O FEMININO PULSANTE CONTRA O "MACHO ASTRAL"}

Nos primeiros versos da música, é possível notar a presença de um acentuado caráter de denúncia, amparada por uma mise-en-scène que apresenta como marca um destacado tom humorístico:

Reclamam do jeito que eu dou risada. Reclamam da minha mão desmunhecada. Reclamam do jeito que jogo o cabelo pra trás, pra trás, pra trás, pra trá... trá... e dizem que a minha voz é bem miada, que não precisa ser tão afeminada. Precisa sim, precisa sim, precisa sim, precisa sim, precisa sim, 
precisa sim... E Inhaí, pode reclamar, eu vou continuar assim afeminada, bem afeminada [...] (CTRL+N, 2018)

Em primeiro lugar, percebemos a ação de dois verbos, conjugados na terceira pessoa do plural, que expressam a ideia de diferenciação a partir de um mecanismo de "rejeição". Quem reclama do jeito que a risada é encenada? Quem diz que a voz não pode ser "miada"? O percurso discursivo, aqui, funciona como uma construção argumentativa que, segundo Charaudeau (2012), “[...] é um resultado textual de uma combinação entre diferentes componentes que dependem de uma situação que tem finalidade persuasiva" (CHARAUDEAU, 2012, p. 207).

É pertinente apontar que a denúncia em tom humorístico e as performances construídas no videoclipe contribuem para essa percepção. Isso se dá com base em uma contra-argumentação, qual seja, a necessidade de ser comedido na maneira de se comportar em sociedade. Parece haver, portanto, uma "regra de etiqueta" que ditaria a forma ideal de os homossexuais se comportarem. Mediante essa percepção, temos a estratégia da refutação, embalada por uma modalidade deôntica, que poderia ser sintetizada pela ideia de que "não só é possível ser afeminada, como é preciso ser". É um claro exemplo de autoafirmação, no sentido de que um território precisa ser demarcado. O detalhe é que não apenas "precisa sim”, como "precisa sim, precisa sim, precisa sim, precisa sim, precisa sim, precisa sim". O sintagma nominal supracitado repetido seis vezes está longe de ser um recurso apenas estilístico, mas uma estratégia discursiva calcada na repetição (CHARAUDEAU, 2010), que visaria acentuar o caráter persuasivo do texto.

Em seguida, temos a informação mais importante do excerto: "E inhaí, pode reclamar, eu vou continuar assim afeminada...”. As reticências indicam a presença novamente da repetição. Mas o que merece destaque é a utilização da expressão "inhaí" que, aparentemente, se situaria em um léxico próprio de uma categoria subjetiva ainda mais estigmatizada na comunidade LGBT+ (os afeminados). Tal estratégia poderia incorrer no fenômeno apontado por Charaudeau (2015) da inclinação do grupo para si mesmo. Acreditamos que tal estratégia é utilizada para a reafirmação identitária, adquirida com base na percepção da diferença existente entre os sujeitos enunciadores e os grupos alheios aos comportamentos destacados pelos primeiros. Esse movimento se dá por meio da plasticidade axiológica que, no entendimento de Paveau (2015), 
primaria em um dispositivo estratégico de ressignificação semântica de estigmatizações. Nesse sentido, Paveau (2015) destaca que "[...] a plasticidade diz respeito em especial aos insultos, e de maneira mais ampla, às estigmatizações...” (PAVEAU, 2015, p. 327).

Assim, a relação interdiscursiva que permeia o termo "afeminada" impõe a ele uma carga semântica negativa, pois, conforme dissertamos ao longo do texto, o que se busca, na maioria das vezes, é a virilidade e a hipermasculinidade. Apesar disso tudo, "Inhaí, que eu vou pintar az'unha mesmo. Inhaí, que eu vou jogar o meu cabelo. Inhaí, sou bicha janeiro a janeiro. Inhaí, que desse grupo eu sou a mais afeminada, bem afeminada [...]" (CTRL+N, 2018). O segundo trecho da música explicita um caso de "resposta capacitante" (PAVEAU, 2015), e nota-se a presença de outro termo axiológico, "bicha", que nos parece ser ainda mais estigmatizado do que "afeminada".

Paveau chama a atenção para dois mecanismos construídos com o incremento da plasticidade axiológica: a ressignificação e o desarme. Ao operar com tal estratégia, o que se percebe em produções artísticas como a obra Afeminada é a discursivização de uma espécie de desconstrução memorialística. A dimensão semântica de um axiológico é construída e compartilhada por uma comunidade, isto é, ela se adentra no interdiscurso. Nesse sentido, a organização discursiva do videoclipe visa quebrar os paradigmas repressores, utilizando a ferramenta do humor como "desarme" ao que os músicos nomeiam como "macho astral". É sabido que o problema da discriminação é algo corrente e pulsante na sociedade brasileira, portanto, faz-se necessário buscar formas de romper as barreiras da intolerância. A dupla CTRL+N se municia do deboche, utilizando, para tanto, um trabalho de fotografia e uma direção de arte e figurinos carregados em tons coloridos e isso, de alguma forma, visaria combater o mundo "sem cores" do totalitarismo heteronormativo. É, notoriamente, um recurso argumentativo que se faz presente pelos arranjos da ironia:

\footnotetext{
O que seria de nós sem uma boa dose de autocrítica nesse mundo de signos e de convenções, mundo que nos obriga a adotar certos papéis sociais e, em decorrência destes, comportamentos mais ou menos codificados? Sem a liberdade de rirmos de nós mesmos e do que não aprovamos na vida em sociedade ainda que o façamos por meio de um riso discreto? (MACHADO, 2014, p. 109)
}

É importante pontuar o caráter deôntico que impera pela necessidade das pessoas se enquadrarem em papéis sociais delimitados. Amparados pelo postulado indicado por 
Machado (2014), o discurso irônico visaria “desamarrar" essas convenções por meio do humor e, em nosso estudo de caso, lançando mão do deboche. A linguista brasileira insere a ironia na condição de estratégia comunicativa. Esse recurso é colocado em prática por meio de usos linguageiros “[...] que têm como objetivo modificar os julgamentos de alguém sobre alguma coisa ou pelo menos mostrar a este alguém que o locutor tem restrições a propósito do alvo da ironia" (MACHADO, 2014, p. 117). Os julgamentos a serem modificados em Afeminada são aqueles que estipulariam padrões de conduta. A crítica se volta, portanto, para aquelas pessoas que "reclamam da mão desmunhecada", "da voz miada" e "do jeito que eu jogo o cabelo pra trás", pois esses trejeitos seriam contrários a um comportamento tido como ideal.

Existem dois pontos destacados por Machado (2014) que merecem a devida atenção. A autora aponta a autocrítica e a liberdade de rir de si mesmo como eixos pertencentes ao discurso irônico. Em Afeminada, o que se vê, tanto na música, quanto no videoclipe, são sujeitos-que-ironizam desarmando seus detratores por meio de um afloramento dos trejeitos, tão combatidos pela heteronormatividade e por um suposto código de conduta construído no interior da comunidade LGBT+. Ao mesmo tempo em que eles conseguem rir de si mesmos, construindo performances que podem ser consideradas exageradas, eles buscam reafirmar seus traços identitários, combatendo uma entidade nomeada de "macho astral", um evidente trocadilho com a expressão baixo-astral. O "macho astral” seria, dessa forma, a personificação daqueles que criam visões estigmatizadas ou estereotipadas e que, por conseguinte, contribuem no processo de interdição discursiva de determinados grupos sociais.

\section{NOTAS SOBRE BIOÉTICA, DIREITO E MORAL: O SER HUMANO E SUA DIGNIDADE}

Ao analisar discursivamente o videoclipe da música Afeminada, percebemos que essa obra artística está longe de ser considerada apenas uma manifestação cultural meramente debochada e bem-humorada. Afeminada se apresenta como uma produção artística que nos ajuda a compreender a noção de direitos humanos, em práticas cotidianas constitutivas de lutas imprescindíveis para garantir o respeito à vida em suas diferentes formas de expressão. 
Com base nos mecanismos construídos no videoclipe, com o incremento da plasticidade axiológica (PAVEAU, 2015) e sua atuação nos imaginários sociodiscursivos (CHARAUDEAU, 2015), percebemos as intenções irônicas dos enunciadores de Afeminada nos processos de ressignificação das formas de expressão dos direitos e das garantias fundamentais. Os discursos militantes de autoafirmação da dupla $\mathrm{CTRL}+\mathrm{N}$ nos levam a pensar na luta pelo direito à identidade, conforme a Declaração Universal sobre Bioética e Direitos Humanos, proclamada pela UNESCO, em 2005; e no princípio da dignidade da pessoa humana, fundamento do Estado Democrático de Direito, nos termos do art. $1^{\circ}$, inciso III, da Constituição Federal de 1988.

Embora a bioética esteja frequentemente relacionada aos procedimentos médicos, tecnológicos e aos avanços das ciências da saúde, entendemos que há uma relação entre as bases da bioética e as formas de expressão no mundo da vida, em suas dimensões psicológicas, sociais, antropológicas e discursivas.

De acordo com Pizzi (2006), o filósofo Edmund Husserl, em suas últimas obras, especialmente, em A crise das ciências europeias (1936), alcunhou o sintagma mundo da vida como tema relevante para a filosofia. O objetivo era contrapor o mundo da vida ao pensamento cientificista que predominava desde meados do século XIX e início do século XX, momento marcado pelo positivismo sociológico, em que se acreditava nas ciências da natureza como única forma admissível de conhecimento. Sabemos que esse termo é resgatado por Jürgen Habermas, posteriormente, trazendo novas perspectivas a respeito do seu conteúdo material. Não aprofundaremos a temática do mundo da vida neste artigo, em razão dos nossos objetivos, mas acreditamos que essa abordagem é interessante para pensarmos as relações entre bioética, discurso e Direito em futuras pesquisas.

Recordamos que o termo bioética é composto a partir de duas palavras gregas bios (vida) e ethikós (ética). A bioética é, por tanto, a ética da vida. De acordo com Roberto Andorno ${ }^{1}$ (2012), o termo bioética permite reunir, em uma mesma disciplina, reflexões sobre temas heterogêneos. Esses temas são interessantes não apenas para a ética médica, mas também são relevantes para o direito, a filosofia e a política. Nas discussões que envolvem os princípios da bioética, um dos questionamentos centrais 
está relacionado ao valor do ser humano em sua corporeidade. Desse valor, é retomado o eterno questionamento a respeito do ser humano sobre si mesmo e sua dignidade.

Andorno (2012) destaca que, em razão da complexidade presente nos avanços biotecnológicos, a bioética surge com características próprias, pois pressupõe uma aproximação, ao mesmo tempo, interdisciplinar, prospectiva, global e sistemática aos novos dilemas. Nas palavras do jurista:

É interdisciplinar, dado que, ao se interessar diretamente pelo valor da vida humana e pelas repercussões sociais dos novos desenvolvimentos, não concerne apenas aos médicos e biólogos, mas também aos juristas, filósofos, teólogos, autoridades públicas, psicólogos, etc. Prospectiva, porque se direciona necessariamente para o futuro da humanidade. Global, porque muitos dos novos desafios não só afetam a indivíduos isolados, mas à humanidade em seu conjunto. Sistemática, porque pretende se organizar como uma reflexão coerente e estruturada, com princípios próprios, e não como uma simples casuística. (ANDORNO, 2012, p. 12, trad. nossa) ${ }^{2}$

Da leitura da Declaração Universal sobre Bioética e Direitos Humanos (2005), extraímos algumas noções que nos parecem relevantes para as reflexões que trazemos em nosso trabalho. Nessa Carta de Valores, reconhecemos as dimensões interdisciplinar, prospectiva, global e sistemática, explicitadas por Andorno (2012), e que nos parecem importantes para a análise do videoclipe Afeminada.

Inicialmente, destacamos o valor da expressão de consciência que aparece na base preambular do documento da UNESCO. As vozes que declaram, em Conferência Geral, se mostram conscientes dos sentidos que devem ser atribuídos à existência, às responsabilidades que assumimos em nossas escolhas e à busca de cooperação. Assim, a Declaração de Bioética se mostra:

\footnotetext{
Consciente da capacidade única dos seres humanos de reflectir sobre a sua existência e o seu meio ambiente, identificar a injustiça, evitar o perigo, assumir responsabilidades, procurar cooperação e dar mostras de um sentido moral que dá expressão a princípios éticos. (UNESCO, 2005, preservamos a grafia original)
}

Posteriormente, destacamos o reconhecimento da dignidade da pessoa humana para o exame das questões que envolvem o respeito universal e a efetividade dos direitos humanos e das liberdades fundamentais. Nesse sentido: 
Reconhecendo que as questões éticas suscitadas pelos rápidos progressos da ciência e suas aplicações tecnológicas devem ser examinadas tendo o devido respeito pela dignidade da pessoa humana e o respeito universal e efectivo dos direitos humanos e das liberdades fundamentais. (UNESCO, 2005, preservamos a grafia original)

Os excertos em destaque nos levam a pensar sobre a urgente pergunta a respeito do ser humano e sobre as identidades que assumimos ao longo da nossa existência. Essas indagações parecem ressoar nas respostas produzidas pelas vozes do videoclipe Afeminada, especialmente, quando enfatizam modos de ser específicos de um grupo que traça seu projeto de autoafirmação identitária. Entendemos que essa afirmação contra o "macho astral", proposta na música, reforça princípios bioéticos que dizem respeito às formas de vida em suas diversas modalidades de expressão.

Segundo Roberto Andorno (2012), o que se coloca em jogo nos dilemas bioéticos da contemporaneidade é a essência em si do ser humano como sujeito,

[...] que se resiste à coisificação em direção à qual parece ser empurrado. $\mathrm{O}$ cenário tecnológico atual dá lugar ao que Jean Ladrière qualifica como "um verdadeiro fenômeno de indução existencial" sobre o ser humano, que começa a ser visto segundo as únicas categorias técnico-científicas e é assim reduzido ao status de coisa que se pode modelar à imagem dos objetos técnicos. (ANDORNO, 2012, p. 68, trad. nossa, aspas do autor) ${ }^{3}$

Sabemos que a produção tecnológica cultural também tem se revelado opressora ao ditar normas de comportamento arbitrárias que são expressas em filmes, programas televisivos, novelas e outras formas de manifestação artística. Assim, o videoclipe Afeminada também parece dar uma resposta às diversas categorias técnico-científicas que induzem esses comportamentos.

A Declaração Universal sobre Bioética e Direitos Humanos nos alerta sobre as fontes de intercâmbio cultural e as diversidades que compõem o legado da humanidade. Esses elementos não devem ser invocados em oposição às liberdades fundamentais. Assim, a Conferência Geral da UNESCO reconhece que:

[...] a diversidade cultural, fonte de intercâmbios, de inovação e de criatividade, é necessária à humanidade e, neste sentido, constitui património comum da humanidade, mas sublinhando que ela não pode ser invocada em detrimento dos direitos humanos e das liberdades fundamentais, [...] (UNESCO, 2005, preservamos a grafia original) 
Andorno (2015, p. 68) considera que, atualmente, a reflexão sobre a noção de pessoa é particularmente importante, uma vez que está alinhada às liberdades fundamentais. Por isso, são propostas duas perguntas, uma que pode ser considerada de natureza ontológica e outra que se alinha a uma perspectivava ética: “o que é pessoa?" ou "qual é o seu valor?" Para um esboço das respostas aos questionamentos citados, Andorno (2012) sugere que retomemos a etimologia da palavra em análise:

\begin{abstract}
O termo em latim persona se formou a partir do grego prosôpon (rosto), que servia tanto para designar o rosto humano em sua realidade física e concreta, como a máscara que levavam os atores, e logo, por metonímia, o papel que a máscara simbolizava. Esta origem da palavra não é casual. O rosto é o que exterioriza a pessoa de modo mais imediato; o rosto, sempre singular e único, expressa apropriadamente o caráter irredutível da personalidade. Como destaca Emmanuel Levinas, o rosto é o meio por excelência para descobrir o infinito que está presente em cada ser humano. (ANDORNO, 2012, p. 69, trad. nossa $)^{4}$
\end{abstract}

No videoclipe Afeminada, é notória a justaposição de rostos e corpos, com barbas, saias e unhas pintadas, que se imiscuem para a abordagem do feminino pulsante que se extrai das vozes que cantam o direito ao corpo alinhado à identidade e dignidade existencial. Essa exteriorização das pessoas que compõem a obra artística parece clamar pelas janelas de visibilidade e pelo sentimento de pertencimento dos corpos que as definem. As diferentes faces femininas corporificadas pelos gays que criam a encenação do vídeo parecem não só debochar do totalitarismo heteronormativo mas, ao mesmo tempo, denunciar suas próprias armadilhas totalitárias. Essas faces, com seus modos de expressão, enfatizam ainda o apoio "apenas das bichas afeminadas que querem gritar pela causa" ([Descrição do videoclipe] CTRL+N, 2018), aspecto interessante para pensarmos a noção de autopertencimento.

Para Andorno (2012), por meio do termo latino "persona" que nos remete à ideia de rosto, há uma busca pela referenciação do ser que pertence exclusivamente a si mesmo (dominus sui). Em outras palavras, trata-se de uma referência que é radicalmente incapaz de pertencer a outro como simples objeto, o que gera um sentimento de autopertencimento. A ideia de "persona" atrelada à noção de rosto nos conduz à reflexão de identidade. Essa noção também se encontra explicitada na Declaração sobre Bioética (2005). Vejamos: "Tendo igualmente presente que a identidade da pessoa tem dimensões biológicas, psicológicas, sociais, culturais e espirituais [...]” (UNESCO, 
2005), o autopertencimento, na visão de Andorno (2012, p. 69-70, trad. livre), “[...] não deve ser considerado em sentido jurídico, pois o Direito não considera o corpo como propriedade da pessoa"5. E assim justifica:

\begin{abstract}
O motivo é muito simples: o corpo não é uma "coisa" externa sobre a que se possa exercer um direito subjetivo como se exerce sobre as coisas. Além disso, entre a pessoa e seu corpo não há, estritamente falando, vínculo jurídico algum, posto que ambas (realidades) se identificam. Em outras palavras, a pessoa não possui um corpo, mas sim ela é um corpo. (ANDORNO, 2012, p. 70, trad. nossa, aspas e itálicos do autor) ${ }^{6}$
\end{abstract}

A relação das pessoas com o corpo parece estar alinhada à natureza em si do sujeito, considerado como unidade. Desse modo, o ser humano “[...] não pode se desdobrar dentro de si mesmo entre um 'sujeito de direito' e um 'objeto de direito', sem que sua unidade mais radical fique afetada" (ANDORNO, 2012, p. 70, trad. nossa) ${ }^{7}$. Portanto, a relação da pessoa com o seu corpo não pode ser imposta pelo direito, pois nessa relação afloram elementos culturais, psicossociais, discursivos, sociológicos e outros que se alinham a noção de identidade e esta, por sua vez, define a existência.

Acreditamos que essas relações entre sujeito, identidade e corpo atravessam também as discussões sobre direito e moral. No videoclipe Afeminada, a dupla paraense formula uma espécie de paródia (MACHADO, 2013) em seu "mantra contra o macho astral" e problematiza essas relações. Por meio da música e das imagens que compõem o vídeo, há uma contestação dos imaginários sociodiscursivos, conforme afirmamos, que fazem parte das matrizes compulsórias, e que, muitas vezes, interferem nas relações que temos com o corpo e com a autonomia de sua expressão.

Carlos Santiago Nino (2017 [1984]) sustenta que o princípio da autonomia, de raiz Kantiana, é um elemento valioso para que possamos refletir a respeito do direito à inviolabilidade da pessoa. Segundo Nino (2017), esse princípio pressupõe uma distinção entre duas dimensões atreladas à moral: uma que é considerada como moral pessoal ou autorreferente e outra que é entendida como moral social ou intersubjetiva.

A moral "autorreferente" é definida como aquela que prescreve ou proíbe certas ações, tendo em vista os efeitos que elas repercutem no caráter moral do próprio agente, que leva em conta certos modelos de virtude. A moral "intersubjetiva", por sua vez, corresponde àquela que prescreve ou proíbe certas ações pelos seus efeitos em relação ao bem-estar de outros indivíduos diferentes do agente. O princípio da autonomia se 
apoia, então, nestas duas dimensões e estipula que somente naquilo que produz desvio da moral "intersubjetiva" poderia ser justificada uma possível ação de interferência do Estado ou de outros indivíduos, sendo inadmissível essa interferência quando se trata de moral "autorreferente".

Nino (2017) enfatiza que o princípio da autonomia possui, ainda, dois desdobramentos diferentes: o primeiro consiste em valorizar positivamente a autonomia dos indivíduos em relação às suas escolhas e materialização de seus projetos de vida, levando em conta a adoção de ideais que fazem parte da moral "autorreferente"; o segundo consiste em "[...] vedar o Estado e, definitivamente, qualquer indivíduo de interferir no exercício dessa autonomia" (NINO, 2017, p. 229, trad. nossa) ${ }^{8}$. Para o jurista argentino, essa abordagem sobre a autonomia se manifesta na livre escolha não somente de pautas que fazem parte da moral "autorreferente", mas também de qualquer outra pauta moral, inclusive as que integram a moral "intersubjetiva".

Acreditamos que o vídeo Afeminada toca esses conceitos como resposta crítica às estruturas de poder que operam dentro de uma lógica de matriz heterossexual. Também acreditamos que o vídeo problematiza a noção de moral social, dado que esta não é universal e nem homogênea, podendo se apresentar com características da moral autorreferencial dentro de uma lógica grupal.

Essa crítica se faz pela plasticidade que envolve o feminino pulsante dentro do vídeo, cantado e performatizado pelos gays, com articulações discursivas que envolvem o componente irônico em seu teor argumentativo. Esse grupo de pessoas parece buscar elementos da noção autorreferente dentro da discursivização do feminino que compõe a identidade social das "bichas afeminadas". Como a moral social não possui natureza universal, nem mesmo dentro do grupo em que aflora, a dupla paraense e os atores que performatizam a música Afeminada parecem problematizar as críticas oriundas das matrizes heteronormativas e, também, aquelas provenientes de alguns segmentos da própria comunidade LGBT+, que buscam nos modelos de virilidade a construção autorreferente, conforme afirmou o pesquisador Alencar (2017). Portanto,

[...] os homens, dotados de características de masculinidades já socialmente legitimadas pela ordem hegemônica, ao desviarem do padrão de comportamento do polo masculino, "ferem" a hierarquia de gêneros, na qual ocupam historicamente espaço privilegiado, e colocam em cena aquilo que não quer ser visto. $\mathrm{O}$ mesmo ocorre na subcultura gay - o homem homossexual que se representa de forma desviante, trazendo para seu polo 
mais traços de feminilidades do que seria "aceito", é também mal visto. Homens e mulheres que vivem feminilidade e masculinidades de formas diversas não são reconhecidos nem representados como verdadeiros e verdadeiras e, por isso, criticam essa rígida concepção binária e categorizante. (ALENCAR, 2017, p. 43, aspas do autor)

Essa crítica proposta por Alencar (2017) nos parece interessante para a reflexão que trazemos sobre a moral social e a moral autorreferente, pois ambas explicitam a ideia de que o "[...] mundo de significações que devem compartilhar os seres de fala no ato de linguagem tem a ver com o circuito externo, espaço onde figuram representações imaginárias da comunidade à qual pertencem" (ALENCAR, 2017, p. 95). No entanto, esse mundo dentro de uma lógica criada pelo grupo, conforme comentamos, não é universal e nem homogêneo. No domínio das artes, essas noções nos parecem relevantes como discussões que surgem dentro das propostas militantes das minorias LGBT+. Assim, o videoclipe Afeminada parece abrir um campo discursivo que provoca uma discussão sobre a significação da autonomia e da dignidade dentro do universo dos Direitos Humanos.

\section{CONSIDERAÇÕES FINAIS}

Ao término da nossa jornada e sabedores de que não esgotamos o horizonte de possibilidades analíticas que giram em torno do videoclipe Afeminada, percebemos que o desafio de unir os estudos do discurso com questões relacionadas à esfera jurídica vale a pena ser enfrentado. Em nosso texto, há uma gama de linhas teóricas que, acreditamos, apresentam pontos de contato, embora estejam situadas em campos do saber distintos.

A plasticidade axiológica, noção propriamente discursiva, atua nos imaginários circulantes com o objetivo de "marcar um território" que se apresenta estancado, tanto por uma heteronormatividade opressora, quanto por um suposto código de conduta que visaria uniformizar o comportamento dos membros da comunidade LGBT+. Afeminada é, portanto, um discurso que se vale daquilo que Paveau nomeia de "Resposta capacitante". Resposta por ser contra discursivo; capacitante por atentar para a necessidade de um grupo ser respeitado em sua subjetividade. 
Vem daí a interface com a Declaração Universal sobre Bioética e Direitos Humanos (2005), que chama a atenção para o direito ao corpo alinhado ao respeito à individualidade existencial, que, conforme indicamos ao longo do texto, recai "nas diferentes faces femininas" encenadas pelos atores sociais presentes no videoclipe. É também por meio desse documento, proclamado pela UNESCO, que buscamos compreender um sentido moral que dá expressão a princípios éticos, por meio de suas ressonâncias autorreferenciais e intersubjetivas.

É importante reconhecer o trabalho da dupla paraense como uma construção discursiva que, com base em Andorno (2012), se volta para o autopertencimento. O deboche que se manifesta mediante as performances "exageradas" é apenas um "verniz", ou, melhor dizendo, uma estratégia discursiva que prepararia o público para uma mensagem séria e urgente: é preciso não apenas respeitar a liberdade de expressão, mas estimular formas de expressão voltadas para a libertação das amarras sociais que impedem o ser humano de manifestar a sua subjetividade.

\section{Referências}

ALENCAR, Venan. Aplicativos de encontros gays: traços identitários de seus usuários em Belo Horizonte. 2017. 130f. Dissertação (Mestrado em Estudos Linguísticos) Faculdade de Letras da UFMG. Universidade Federal de Minas Gerais, Belo Horizonte.

ALENCAR, Venan. Resistência a padrões e normas em aplicativos de encontros gays. In: Revista Interfacis, Belo Horizonte. v.3, n.2, 2017, p. 57-70.

ANDORNO, Roberto. Bioética y dignidad de la persona. 2. ed. Versión española ampliada y actualizada del texto original en francés: La bioéthique et la dignité de la personne, Presses Universitaires de France, París, 1997. Madrid: EDITORIAL TECNOS (GRUPO ANAYA, S.A.), 2012.

BRASIL. Constituição da República Federativa do Brasil, 1988. Texto Constitucional de 5 de outubro de 1988 com as alterações adotadas pela emenda constitucional $n^{\circ} 108$ de 26 de agosto de 2020. Brasília: Senado Federal. Disponível em: < http://www.planalto.gov.br/ccivil_03/constituicao/constituicao.htm >. Acesso em: 19 jan. 2021.

CHAMON JÚNIOR, Lúcio Antônio. Filosofia do Direito na Alta Modernidade. Incursões teóricas em Kelsen, Luhmann e Habermas. Rio de Janeiro: Lumen Juris, 2005. 
CHARAUDEAU, Patrick. Discurso político. Trad. Dilson Ferreira da Cruz e Fabiana Komesu. 2. ed. São Paulo: Contexto, 2013.

CHARAUDEAU, Patrick. Identidade linguística, identidade cultural: uma relação paradoxal. Trad. Clebson Luiz de Brito e Wander Emediato de Souza. In: LARA, Gláucia Proença, LIMBERTI, Rita Pacheco (Orgs.). Discurso e desigualdade social. São Paulo: Contexto, 2015, p. 13-29.

CHARAUDEAU, Patrick. Linguagem e discurso: modos de organização. Coordenação da equipe de tradução Angela M. S. Corrêa e Ida Lúcia Machado. $2^{a}$ ed., $1^{a}$ reimpressão. São Paulo: Contexto, 2012.

CHARAUDEAU, Patrick. O discurso propagandista: uma tipologia. Trad. Emília Mendes e Judith Ana Aiala de Mello. In: MACHADO, Ida Lucia, MELLO, Renato. Análises do Discurso Hoje, Vol 3. Rio de Janeiro: Nova Fronteira (Lucerna), 2010, p. 57-78.

CTRL + N (ANDERSON, Nigel; FRANÇA, Haroldo). Afeminada. Participação Especial: Rico Dalasam e Coletivo Animalia. Videoclipe lançado no dia 13 de julho de 2018. Disponível em: 〈https://www.youtube.com/watch?v=XHLCRh1Oevg>. Acesso em: 14 jul. 2018.

DOL. Duo paraense CTRL+N lança música e clipe de 'Afeminada'. Assista! DOL. Entretenimento/música. 13 jul. 2018. Disponível em: <https://www.diarioonline.com.br/entretenimento/musica/noticia-523379-duo-paraensectrln-lanca-musica-e-clipe-de-afeminada-assista.html>. Acesso em:13 jul. 2018.

FIGUEIREDO, Adriana do Carmo; ARCANJO, Fábio Ávila. O FEMININO PULSANTE NO VIDEOCLIPE AFEMINADA DE CTRL+N: Notas sobre direito, discurso e moral. In: BAHIA, Alexandre Gustavo Melo Franco de Moraes [et al.]. Caderno de resumos: III Congresso de Diversidade Sexual e de Gênero (3: 2018: Belo Horizonte, MG), p. 813-815.

HABERMAS, J. Teoría de la acción comunicativa. Tomo II: Crítica de la razón funcionalista. Madrid: Taurus, 1987.

HUSSERL, Edmund. Crisis de las Ciencias Europeas y la Fenomenología Transcendental. Trad. y estudio preliminar: Julia V. Iribarne. 1 ed. Buenos Aires: Prometeo Libros, 2008.

KANT, Immanuel. Fundamentação da Metafísica dos Costumes. Trad. Paulo Quintela. Lisboa: Edições 70, LDA, 2007.

MACHADO, Ida Lucia. Parodie et analyse du discours. Paris: L'Harmattan, 2013.

MACHADO, Ida Lucia. A ironia como estratégia comunicativa e argumentativa. In: Bakhtiniana, São Paulo, Número 9 (1), Jan./Jul. 2014, p. 108-128. 
NINO, Carlos Santiago. Ética y Derechos Humanos. Un ensayo de fundamentación. 2. ed. Buenos Aires: Editorial Astrea SRL, 2017.

ORGANIZAÇÃO DAS NAÇÕES UNIDAS (ONU). Declaração Universal dos Direitos Humanos. Paris, 1948. Proclamação pela Assembleia Geral das Nações Unidas em Paris, através da Resolução 217 A (III) da Assembleia Geral. Disponível em: <http://www.dudh.org.br>. Acesso em: 10 jul. 2018.

ORGANIZAÇÃO DAS NAÇÕES UNIDAS PARA A EDUCAÇÃO, CIÊNCIA E CULTURA (UNESCO). Declaração Universal sobre Bioética e Direitos Humanos. Adotada por aclamação no dia 19 de Outubro de 2005 pela $33^{a}$ sessão da Conferência Geral da UNESCO. Disponível em: 〈http://unesdoc.unesco.org/images/0014/001461/146180por.pdf〉. Acesso em: 10 jul. 2018.

PAVEAU, Marie-Anne. Linguagem e moral: uma ética das virtudes discursivas. Trad. Ivone Benedetti. Campinas, SP: Editora da Unicamp, 2015.

PIZZI, Jovino. O mundo da vida. Husserl e Habermas. Ijuí: Editora Unijuí, 2006.

Recebido em: 31/01/2021

Aceito em: 15/04/2021

\footnotetext{
1 Importante comentar que Roberto Andorno foi membro do Comitê Internacional de Bioética da UNESCO, como representante da Argentina (1998-2005). Na ocasião, participou da redação da Declaração Internacional de Dados Genéticos Humanos (2003) e da Declaração Universal sobre Bioética e Direitos Humanos (2005). Em 2016, participamos de um Seminário doutoral na Facultad de Derecho, na Universidad de Buenos Aires, ministrado pelo professor Dr. Roberto Andorno. Nesse seminário, discutimos as relações entre Bioética e Direito.

${ }^{2}$ No original: "Es interdisciplinaria, ya que, al interesarse directamente por el valor de la vida humana y las repercusiones sociales de los nuevos desarrollos, no concierne sólo a los médicos y biólogos, sino también a los juristas, filósofos, teólogos, autoridades públicas, psicólogos, etc. Prospectiva, porque mira necesariamente hacia el futuro de la humanidad. Global, porque muchos de los nuevos desafíos no sólo afectan a individuos aislados, sino a la humanidad en su conjunto. Sistemática, porque pretende organizarse como una reflexión coherente y estructurada, con principios propios, y no como una simple casuística”.

${ }^{3}$ No original: [...] "que se resiste a la cosificación hacia la cual parece ser empujado. El escenario tecnológico actual da lugar a lo que Jean Ladrière califica como 'un verdadero fenómeno de inducción existencial' sobre el ser humano, que comienza a ser visto según las únicas categorías tecnocientíficas y es así reducido al estatus de cosa que se puede modelar a imagen de los objetos técnicos".
} 


\footnotetext{
${ }^{4}$ No original: "El término latín persona se ha formado a partir del griego prosôpon (rostro), que servía tanto para designar el rostro humano en su realidad física y concreta, como la máscara que llevaban los actores, y luego, por metonimia, el papel que la máscara simbolizaba. Este origen de la palabra no es casual. El rostro es lo que exterioriza a la persona del modo más inmediato; el rostro, siempre singular y único, expresa apropiadamente el carácter irreductible de la personalidad. Como lo destaca Emmanuel Levinas, el rostro es el medio por excelencia para descubrir el infinito que está presente en cada ser humano".

${ }^{5}$ No original: "Esta autopertenencia tampoco debe entenderse en sentido jurídico. El derecho no considera el cuerpo".

${ }^{6}$ No original: "La razón es muy sencilla: el cuerpo no es una «cosa» externa sobre la que se pueda ejercer un derecho subjetivo como el que se ejerce sobre las cosas. Más aún, entre la persona y su cuerpo no hay, estrictamente hablando, vínculo jurídico alguno, puesto que ambas realidades se identifican. En otras palabras, la persona no posee un cuerpo, sino que ella es un cuerpo".

${ }^{7}$ No original: "El ser humano no puede desdoblarse dentro de sí mismo entre un «sujeto de derecho»y un «objeto de derecho» sin que su unidad más radical quede afectada".

${ }^{8}$ No original: [...] "en vedar al Estado, y en definitiva a otros individuos, interferir en el ejercicio de esa autonomía".
} 